\title{
MARKETING
}

\section{Woody Allen e o mercado}

nstrumento fundamental do marketing e conceito indispensável para a tomada de decisões, a segmentação de mercado pode guardar aspectos insuspeitados - e muito pouco nobres. Inspirado por um filme de Woody Allen, este artigo propõe-se a desconstruir o conceito e mostra que, apesar do recente discurso de reconhecimento e respeito às diferenças, ele mascara e reproduz práticas históricas de discriminação e dominação.

por Marcelo Milano Falcão Vieira Ebape/FGV, Propad/UFPE, Jorge Francisco Bertinetti Lengler Unisc, PPGA/EA/UFRGS e Roberto C. Fachin PUC-Minas, Fundação Dom Cabral

A ficção pode ser um atalho seguro para a apreensão da realidade. Um filme - uma comédia, por que não? - pode ser um bom ponto de partida para quem deseja examinar certas sutilezas da vida corporativa.

Aqui, a realidade a ser apreendida é a que cerca 0 conceito de segmentação de mercado, uma das ferramen- tas mais utilizadas na tomada de decisão nas organizações, e o filme é Desconstruindo Harry, de Woody Allen, lançado em 1997. Por ele inspirados, debruçamo-nos sobre as recentes práticas de segmentação, evidenciando alguns elementos que podem passar despercebidos ao observador desavisado. 
Questão de foco. Em Desconstruindo H arry, um personagem interpretado por Robin Williams aparece fora de foco em frente à câmera. Ao primeiro julgamento, a falta de foco pode parecer ao espectador um problema técnico. Aos poucos, nota-se que é o próprio personagem que está "fora de foco no mundo real", fora do foco de sua vida. Essa seqüência poderia ser entendida como a essência do trabalho de Allen: os indivíduos são descentrados, fora de foco em uma realidade manipulada por constantes simulacros.

O filme não foge ao estilo das obras anteriores do diretor. Manipulando a realidade, Woody Allen introduz um sentimento dissonante no plano real, deixando clara a intenção de instalar uma realidade paralela à vida dos personagens e mostrando incessantemente a fragilidade dos personagens. A fal ta de clareza, a fragmentação, a inexistência de uma narrativa linear e, sobretudo, a abordagem de temas relacionados às minorias fazem a tônica da desconstrução de Harry Block, o personagem principal, em pouco mais de hora e meia de projeção.

\section{O conceito e as práticas de segmentação}

\section{de mercado sufocam determinados grupos}

\section{de indivíduos, que acabam marginalizados}

\section{por um discurso dominante.}

Assim como Woody Allen exercita a desconstrução desvendando facetas insuspeitadas dos personagens, procuraremos desconstruir o conceito de segmentação de mercado, a fim de desvendar o que há de oculto no tema. É importante ressaltar que desconstrução não significa destruição. Desconstruir é, antes, desmontar, olhar as entrelinhas para analisar e entender elementos subjacentes à prática e ao discurso que, quase sempre, têm a voz do contador da história. Os exercícios de desconstrução visam, portanto, a revelar outros significados do discurso dominante, contrapondo-seà concepção moderna de significados únicos e herméticos.

Fragmentando o mercado. Considerado uma das ferramentas capitais do marketing, o conceito de segmentação de mercado começou a se projetar no meio acadêmico e ge rencial a partir da segunda metade do século XX. Seu objetivo era claro: diante da impossibilidade de atingir todos os consumidores - devido à dispersão geográfica e à heterogeneidade de necessidades, valores, gênero ou padrões culturais-, as organizações deveriam direcionar seus esforços para grupos específicos de consumo. Por meio dessa filosofia empresarial, o mercado total fragmenta-se em inúmeros micromercados.

Se em um primeiro momento 0 conceito de segmentação circunscrevia-se à localização geográfica e às características demográficas, ao longo do tempo elepassou a incorporar questões atinentes ao perfil psicológico dos consumidores e aos benefícios esperados em relação ao produto. Firmou-se, assim, como instrumento capaz de fornecer subsídios para a tomada de decisão quanto ao composto mercadológico.

0 presente esforço de desconstrução leva-nos a acreditar que o conceito de segmentação de mercado e sua prática encerram significados não revelados. Em uma primeira leitura, pode-se imaginar que a segmentação inclui em seu bojo um conjunto de atores e vozes normalmente marginalizados, pouco ou raramente ouvidos. Entretanto, o processo de desconstrução tornase mais profundo se considerarmos a hipótese de que os significados embutidos no conceito e nas práticas de segmentação de mercado sufocam determinados grupos de indivíduos, queacabam marginalizados pelo discurso dominante.

Dentre os grupos marginalizados estão, em especial, as minorias: sob a ótica de grupos consumidores, elas são vistas pela indústria como grupos "segmentáveis por suas características específicas". A desmontagem do conceito, portanto, conduz à conclusão de que a segmentação de mercado com base em al gumas características específicas - como etnia e sexo - são manipulações da própria intencional idademercadológica das organizações.

Para verificar tal hipótese, é essencial reexaminar as bases mais utilizadas no processo de divisão dos mercados consumidores, especificamente as questões referentes à etnia e ao gênero - questões baseadas, respectivamente, nos binários branco / negro e homem / mulher. 
Segmentação por etnia. 0 conceito de etnia refere-se à delimitação de um grupo humano segundo seus valores, formas de se vestir, religião e linguagem, entre outras características.

A emergência da população negra como segmento de consumo determinou que esse grupo passasse a ser considerado como possível oportunidade de negócios para o setor produtivo. Entretanto, éoportuno rever a traj etória dessa população ao longo dos últimos anos da história do país.

Da mesma forma como os negros norte-americanos, a história do negro no Brasil é marcada pela escravidão, pelo sofrimento e pelo preconceito. Mesmo depois da abolição da escravatura, os negros brasileiros evoluíram relativamente pouco em sua condição econômica. Mais de cem anos após a assinatura da chamada Lei Áurea, os resultados da escravidão ainda se refletem nas desigualdades entre negros, pardos e brancos. Do total de negros da população brasileira, $81 \%$ estão nos estratos sociais D e E, e $97 \%$ têm renda inferior a dez salários mínimos. 0 rendimento dos negros é, em média, 37\% inferior ao dos brancos, enquanto os considerados pardos recebem rendimentos $32 \%$ inferiores aos brancos. Comparando-se a expectativa de vida dos brancos em relação à dos negros, verifica-se que os primeiros vivem, em média, 66 anos, enquanto os negros e pardos têm uma expectativa de vida de 59 anos.

A discriminação social que acompanha a discriminação econômica pode ser percebida em ações individuais, em provérbios populares, enfim, no dia-a-dia da sociedade brasileira. O cotidiano, assim, vai contra a idéia, muitas vezes defendida, deque o Brasil é uma democracia racial: a realidade prova que o que existe no país é uma tolerância racial, porém com a permanência do preconceito. Há uma discriminação inconsciente e institucionalizada pela própria língua portuguesa palavras como "denegrir" e expressões como "a coisa está preta" são alguns dos exemplos mais imediatos. Há, adicionalmente, um gigantesco abismo entre a cultura negra ea branca.

Entretanto, quando se registram cifras e prognósticos sobre o poder de compra da população negra no Brasil, o "negro" passa a existir de verdade para o homem de marketing e a ser objeto de práticas de segmentação de mercado. Os números referentes à população afro-brasileira por si sós serviriam para justificar a importância de trabalhos que revelassem às empresas os padrões de consumo dessa parcela da

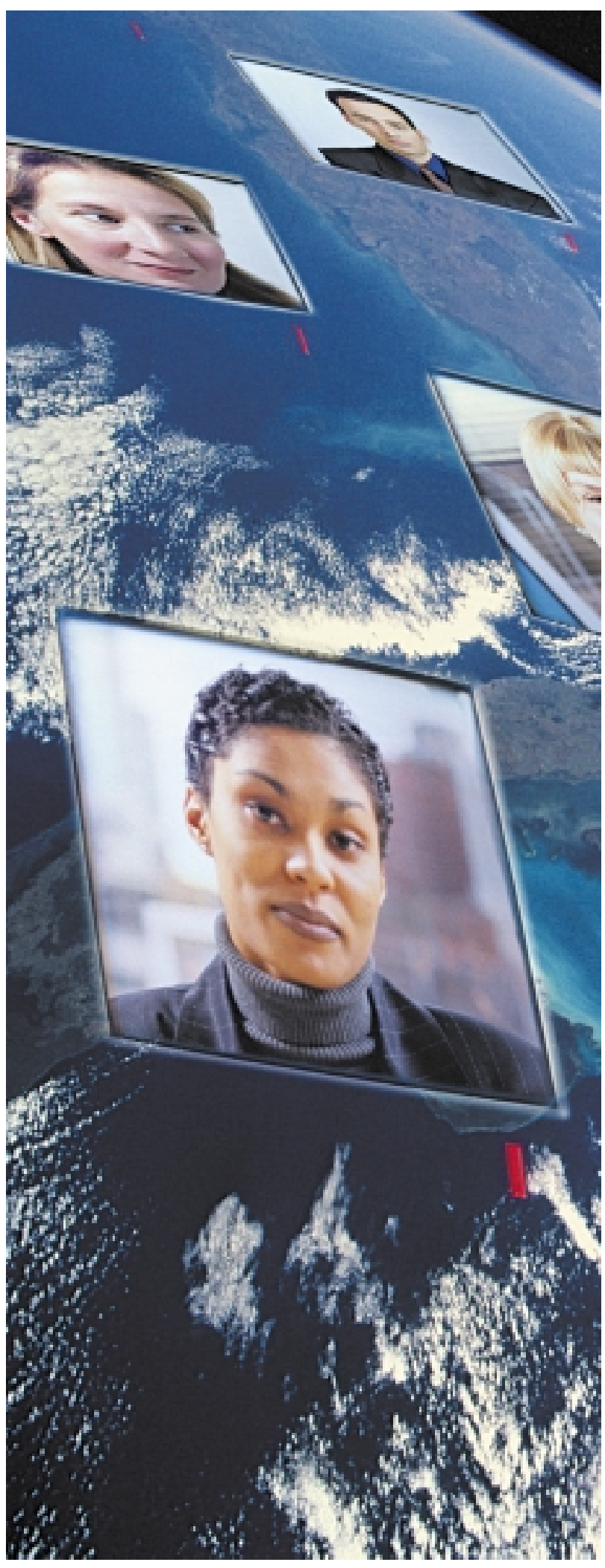


população brasileira. De acordo com os resultados de pesquisa realizada pela agência Grottera, negros e pardos correspondem a 69 milhões de brasileiros. 0 país é a maior nação mestiça do mundo, superando nesse aspecto os EUA - 34 milhões - e nações africanas, como a África do Sul - 35 milhões - e o Congo - 45 milhões. A chamada classe média negra brasileira, que corresponde a 7 milhões de habitantes, tem uma renda média mensal de $R \$ 2,3$ mil, totalizando uma renda anual de $\mathrm{R} \$ 46$ bilhões, com cerca de R\$ 6 bilhões anuais excedentes para o consumo de produtos que não os considerados básicos. Em virtude de tal cenário, as indústrias de bens de consumo iniciaram, na década de 1980, esforços para colocar no mercado produtos e serviços que supostamente atendessem às expectativas desse conjunto de consumidores.

As tentativas de identificar um perfil étnico de consumo garantem que a falta de produtos direcionados para o segmento negro pode ser atribuída a um desconhecimento das diferenças culturais que caracterizam esse grupo.

Alguns estudos afirmam que os consumidores negros são mais leais a marcas quando adquirem al imentos, bebidas e produtos para a casa, privilegiando a qualidade do produto queconsomem. Os mesmos estudos destacam queir às com-

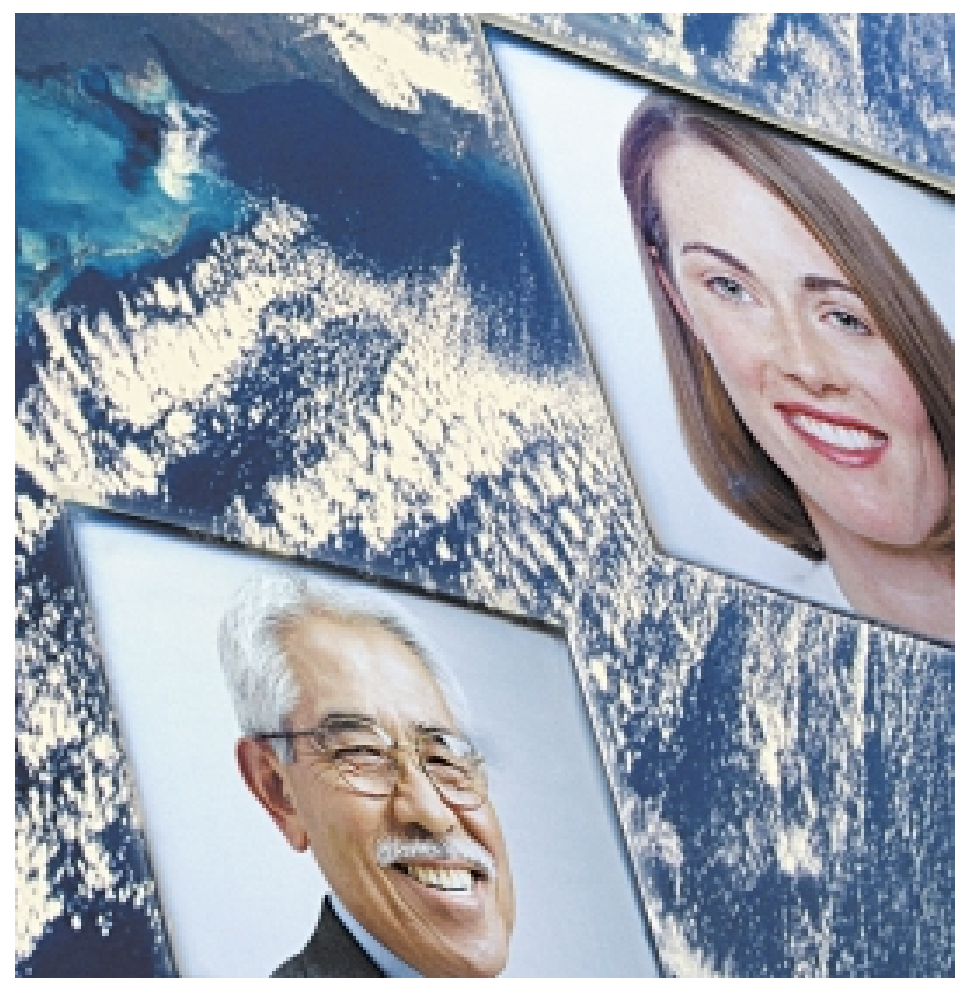

pras é uma das atividades preferidas desse segmento. Especula-se, inclusive, sobre a existência de uma consciência de grupo entre os negros brasileiros, com necessidades, valores e aspirações de consumo específicas.

Ávidas por novas oportunidades de mercado que possam Ihes render resultados positivos, as indústrias de bens de consumo lançam-se em busca do consumidor negro, colocando no mercado "produtos eserviços específicos para esse segmento". A inquietação empreendedora do setor produtivo em conhecer esse "novo" consumidor revela os preconceitos.

Mas o que há de tão específico em consumidores negros que justifique a elaboração de produtos diferentes aos dos brancos? Tecnicamente, não há qualquer tipo de impedimento no uso de produtos "não-segmentados para negros" por parte de pessoas da cultura afro-brasileira. Assim, 0 argumento que sustentamos aqui é de que a segmentação de mercado pela etnia ou raça tem, em si mesma, um apelo discriminatório, oriundo das relações sociais históricas entrenegrose brancos, em que os primeiros desempenhavam papéis secundários ou dominados, enquanto ao segundo grupo cabia 0 status de dominante ou opressor.

Da forma como tem sido tratado pelo setor produtor de bens de consumo e serviços, o segmento de consumidores negros e pardos- ou não-brancos - parece ter assumido o direito da condição soberana deconsumidor, capaz de entrar no mercado de consumo e participar dos processos de socialização a partir do momento em que reuniu condições financeiras para tal. 0 discurso dominante, entretanto, aborda a segmentação de mercado como demonstração de respeito às etnias consideradas minoritárias, por oferecer-Ihes valores por meio de produtos e serviços específicos.

Segmentação por gênero. Ao analisar a segmentação de mercado com base no gênero, constatamoso crescimento das mulheres na população economicamente ativa brasileira, fenômeno identificado por institutos de pesquisas. Em 1950, 85\% da população economicamente ativa no Brasil era composta por homens, eapenas 15\% por mulheres. Em 1995, as mulheres já detinham $45 \%$ das vagas do mercado de trabalho. 
Com rendimentos crescentes, as mulheres ocupam hoje cargos anteriormente destinados aos homens etêm nível educacional superior ao deles. Nos EUA, 8 milhões deempresas pertencem a mulheres e cerca de $30 \%$ das mulheres casadas que trabalham fora ganham mais do que o marido. As muIheres ocupam, ainda, 59\% dos cargos de professores-assistentes em universidades. Além disso, as mulheres tomam ou influenciam significativamentea maioria das decisões de compra do casal, no que diz respeito à moradia, assistência médica, automóveis ou pacotes de viagens. Diante de tais números, o mercado feminino constitui-se em um excelente segmento a ser explorado pelas organizações.

Contudo, a maneira como as organizações exploram esse segmento evidencia uma das formas mais antigas edisseminadas dediscriminação da cultura ocidental: a dominação e supremacia do masculino sobre o feminino. Grande parte das peças publicitárias veiculadas com o objetivo de conquistar o público consumidor feminino apresenta mulheres em situação de submissão em relação ao homem. Veja-se o personagem JoeCamel, personificado nas campanhas publicitárias da companhia de cigarros norte-americana RJR. Joe, um camel o que assume a figura humana, é maior que suas parceiras e desempenha papéis demaior prestígio que elas. Invariavelmente, as mulheres que contracenam com Joe Camel são garçonetes ou dançarinas que chamam a atenção apenas por seus atributos físicos.

$\mathrm{N}$ a divulgação de produtos de uso doméstico, tais como eletrodomésticos, produtos de higiene e limpeza e até mesmo alimentos, o homem ocupa o papel principal nas histórias que são contadas. Apesar do discurso feminista que as organizações pregam, parece ainda não ter havido a ruptura definitiva do status quo definidor das relações de poder entre o masculino e o feminino no que se refere à prática do conceito de segmentação de mercado.

Respeito ou discriminação? A contribuição deWoody Allen, por meio do filme Desconstruindo Harry, é significativa a este trabalho. A presente crítica ao conceito de segmentação de mercado assenta-se justamente sobre os artifícios utilizad os pelo cineasta na desconstrução do personagem Harry
Block. Um olhar mais atento revela que, por trás das práticas de segmentação, há um instrumento de dominação. Grande parte do edifício teórico de marketing, sobretudo no que se refereà segmentação demercado, éanterior à década de 1990 e é marcado pelo acorde monovocal da cultura wasp. Mais recentemente, novas correntes começaram a trazer luzes para a questão, buscando combater a hegemonia de um mundo predominantemente branco, masculino e instruído.

\section{apresenta mulheres em situação de}

\section{submissão em relação ao homem.}

Woody Allen soube trabalhar o propósito da revelação das vozes oprimidas. É necessário lembrar a lógica segundo a qual o cliente é o resultado da equação "pessoa + poder de compra" - assim como um soldado éapenas "pessoa +arma". É preciso lembrar, ainda, que muitos grupos só foram considerados na segmentação quando passaram a ter dinheiro para comprar produtos e gerar lucros; que as mulheres só foram vistas como consumidoras quando começaram a ganhar dinheiro para garantir sua própria decisão e pagar por ela. Por sua vez, os negros no Brasil só começam a ser considerados porque hoje têm um poder aquisitivo maior, constituindo uma classe que interessa ser conquistada.

Por algum tempo, a marginalização no Brasil ainda vai continuar com os idosos e homossexuais - diferentemente de outros países, nos quais seu poder de compra éal tamente disputado, o que talvez seja também confundido com respeito pelas minorias.

Aos executivos, empresários e profissionais de marketing cabe a responsabilidade de manter um permanente processo de reflexão e o questionamento dos processos organizacionais que, legitimados por práticas de mercado, escondem a dominação daqueles que contam a história sobre aqueles que têm sua voz omitida. 